\title{
THERMAL NECROSIS - EXPERIMENTAL INVESTIGATION ON THERMAL EXPOSURE DURING BONE DRILLING PROCESS
}

\author{
Ajish T.N ${ }^{1}$, Govindan $P^{2}$ \\ ${ }^{1}$ M.Tech AMD student, Government College of Engineering, Kannur, India \\ ${ }^{2}$ Assistant Prof. (MED), Government College of Engineering, Kannur, India
}

\begin{abstract}
The process of bone drilling is an essential part of internal immobilization in orthopaedic and trauma surgery. So drill bit design also plays a vital role in surgery. Improper drill bit parameters will seriously affect the bone tissues and results thermal necrosis. This paper investigates the main concern of thermal necrosis during bone drilling.
\end{abstract}

Keywords:-Thermal necrosis, Bonedrilling, Drill parameters

\section{INTRODUCTION}

Drilling of human bone for bone fixation is common in nature. Most of orthopedic surgery includes drilling holes in bone for fixing screws for anchor plates. So during bone drilling process, it will cause to damage the surrounding tissues. The success such problem is mainly depend upon quality of drilling. Tool geometry is an important criterion for such drilling procedure. This makes difficulty for making accurate instruments. So in such situations, we have a clear idea about tool geometry for bone drilling process and how it will reduces thermal necrosis. In traditionally bone drilling is very complicated process. Because of its large tool bit diameter. It will inversely affect the strength of bone. If the drilled hole has a large diameter it will also affects to increase the temperature during drilling. So many research studies are going on this topic.
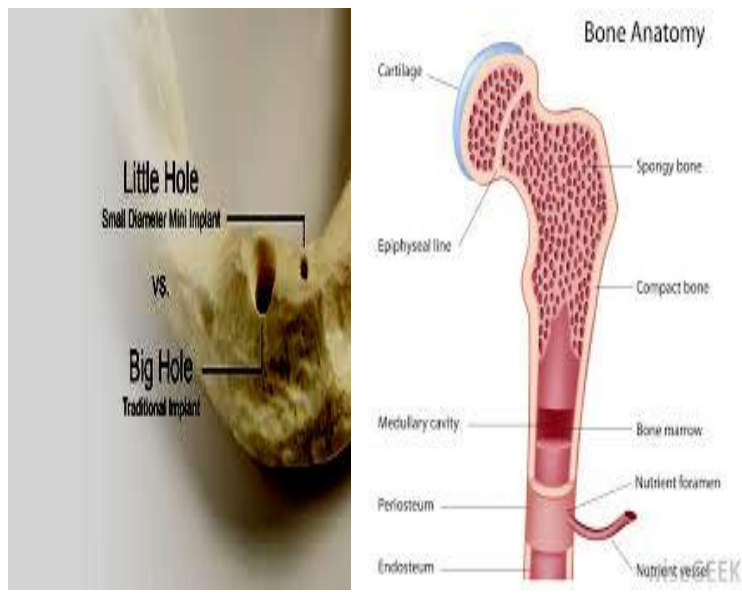

Fig 1: (a) drilled hole on bone 1(b) cross-sectional view of bone [2]

The main purpose for this paper is to identify what are the major reasons for thermal necrosis and proper tool geometry for reduce thermal affects during micro bone drilling. All these things are included in this paper.

\section{PRINCIPLE \& METHODOLOGY}

The basic principle behind the joining of bones is drilling in to the bone and titanium plates were fixed for proper positioning. The main parameters for this drilling process id feed, depth of cut and speed.
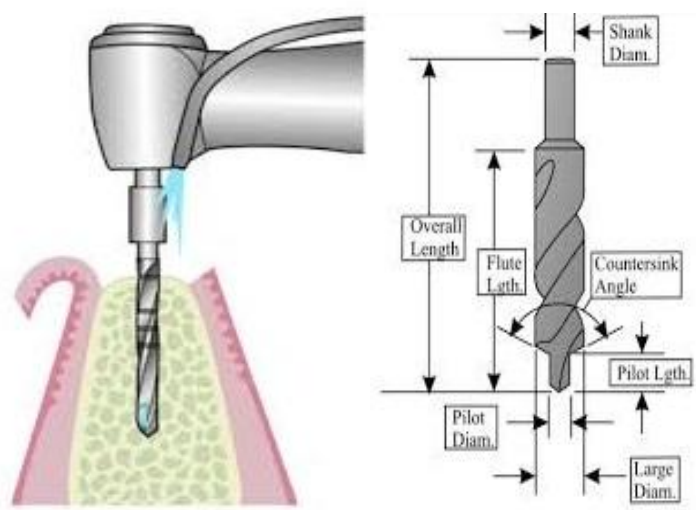

Fig 2 (a) Bone drilling process 2(b) drill bit specification [3]

Drill bit specification is prescribed in fig 2. When drill bit touches the outer bone surface Periosteum. If we drill a hole on bone for an implant, entering side has the presence of burrs. These burrs may affect at the time of implant the titanium plates. And it is also creates low residual stress inside of the hole.

\section{EXPERIMENTAL SET UP}

An experimental work is carried out by G.J.M. Tuijthof [2] in a goat bone for analyzing temperature affects. Fig shows the experimental setup. G.J.M Tuijthof uses an electromotor (Type 2559598, Gmünd, Austria) [2] and it is mounted on (Type TH2730 04243 - 2001, Thümler, Nürnberg, Germany) [6] that was equipped with a load cell and which is possible to move the motor with different load cells at different feed rates. Electro motor's shaft is directly attached with a conventional drill clamp, which in turn allowed clamping of the drill bits. This gives the maximum deviation 
from drill bit to drill axis. The feed rate was set at 0.58 $\mathrm{mm} / \mathrm{s}$ and the drilling speed was kept at $200 \mathrm{rpm}$.

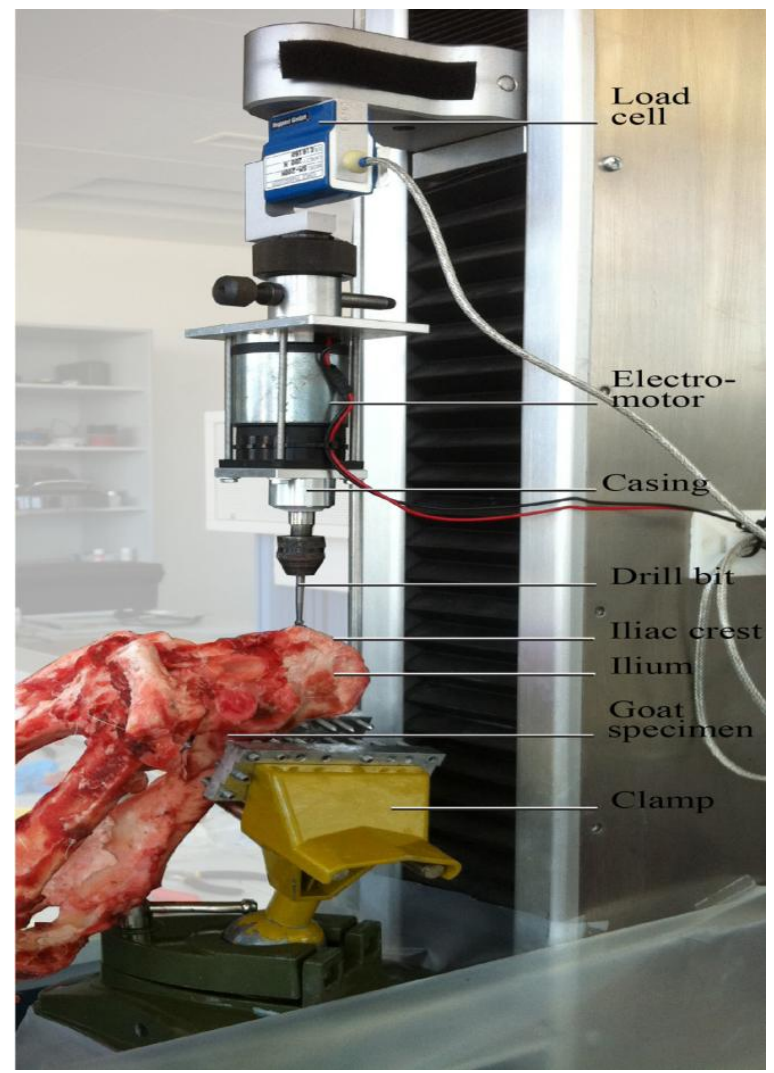

Fig 3 experimental set up [2]

The researches Hillery and Shuaib[6] were conduct an experiment with k-type thermocouple were placed inside the drill bit for measure the temperature changes. The machine used for this experiment is a modified Emco milling machine with approximately 50-2500 rev/min [6] The active elements of the measuring cantilevers were Kwoya KFD-2D16-L30-type strain gauges with pre-attached lead wires in a half bridge circuit with separate identical compensation gauges [6] and by using this setup he arrange the feed rates in as 400,600,800, 1000, 1200, 1400, 1600, 1800 and 2000 $\mathrm{rev} / \mathrm{min}$. These were chosen in order to go below and above the speeds recommended in the literature for the drilling of bone.

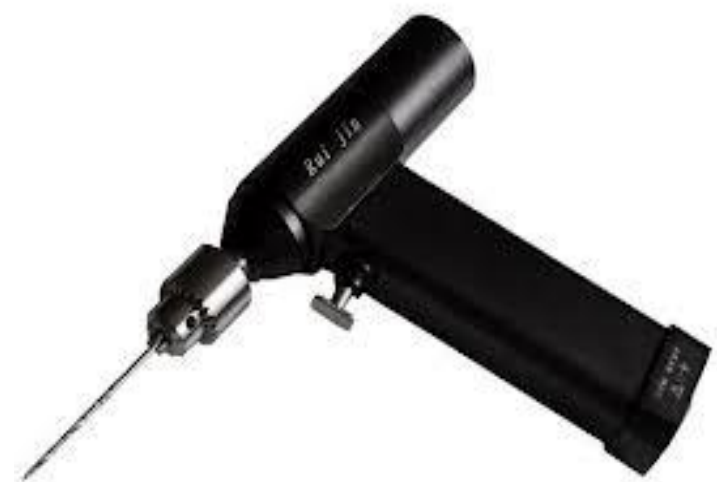

Fig 4 Human surgical Electric Auto cleavable hand drill [5]

\begin{tabular}{|l|l|}
\hline specification & $14.4 \mathrm{~V}$ \\
\hline Working Voltage & $\geq 20 \mathrm{~W}$ \\
\hline Output Power & $\mathrm{AC} 220 \mathrm{~V}, 50 \mathrm{~Hz}$ \\
\hline Input Power & $14.4 \mathrm{~V}, 900 \mathrm{~mA}$ \\
\hline Output Power & $14.4 \mathrm{~V}$ \\
\hline Voltage & 3 hours \\
\hline Charging time & \\
\hline
\end{tabular}

\section{RESULT AND DISCUSSIONS}

Increased drill diameter, rotational speed, feed, depth of cut, drilling forces is the major parameters for thermal necrosis during bone drilling. It is generally classified as drilling parameters and drilling specifications. This is due to affect of following reasons.

\section{Effect of Drilling Spindle Speed:}

Feed rate and speed is an important factor during bone drilling. Many research scholars identify the relation between these feed and speed. Thompson [4] found that the temperature increases at $40 \mathrm{c}$ to $47 \mathrm{c}$ for $6 \mathrm{~mm}$ drilling depth and $63 \mathrm{c}$ to $72 \mathrm{c}$ for $7 \mathrm{~mm}$ drilling depth. The drill bite with increasing speed from $1000 \mathrm{rpm}$ to $4000 \mathrm{rpm}$ from conducting the experimental work by

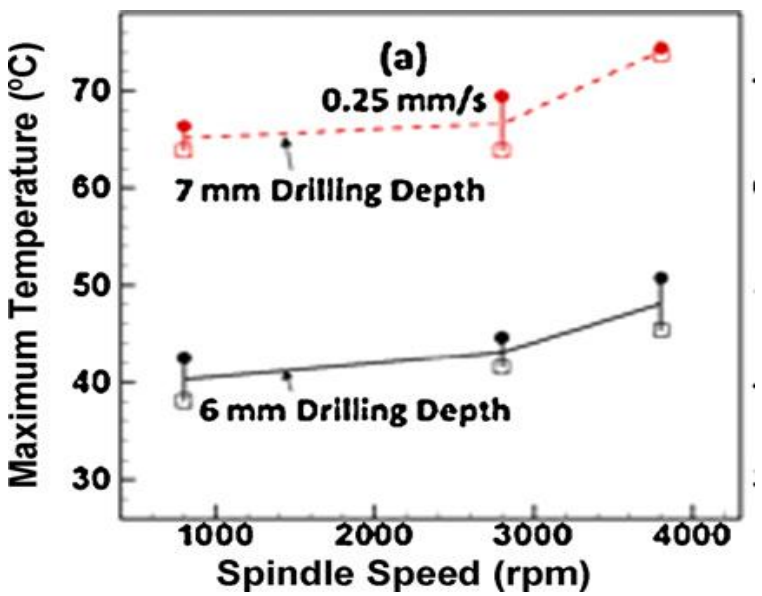

Fig 5 Maximum temperature graph for $0.25 \mathrm{~mm} / \mathrm{s}$ feed rate [3]

Wendong [6] identifies the force acting on the bone is reduces when rotational speed increases. Similarly in the case diameter, minimum diameter of cutting tool posses minimum thrust force. Hillery and Shuaib[1] showed that there is a significant decrease in the temperatures generated during bone drilling with increasing drill speed from 1000 rpm to $4000 \mathrm{rpm}$ with a drill diameter of $3.2 \mathrm{~mm}$. Drilling depth and cortical bone thickness:

Bone thickness is also an important factor during drilling. Increased temperature mainly because of greater cortical thickness and greater drilling depth. Hillery and Shuaib [1] find outs from his experimental work the bovine bone posses more higher temperature as compared to human bone with same parameter conditions and explained about this 
result due to the thickness variation of bone. Burak Ozdoganlar [3] identifies that different animal possess different bone thickness at same time of drilling.

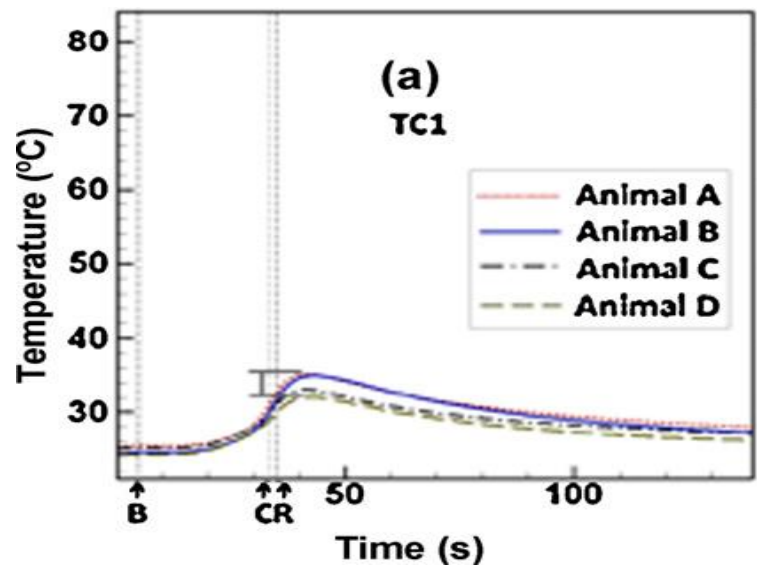

Fig 6 Temperature distribution for different animals [3]

Fig 6 shows the thermal history of four different classes of animals at 3800rpm and $025 \mathrm{~mm} / \mathrm{s}$ feed rate. [6] The variation in temperature for first set of animals is almost $4{ }^{\circ} \mathrm{C}$ and second set of animals possess almost $13{ }^{\circ} \mathrm{C}$ of temperature difference. It is well established in the literature that tissue characteristics such as bone density vary between animals of the same species due to many parameters such as nutrition, age, and history of physical activity. [3] In addition, mechanical properties of the bone may vary with depth of cut.

\section{CONCLUSION}

This paper mainly includes the affect of thermal necrosis due to cutting parameter like speed, feed and depth of cut.

- To reduce the affect of thermal necrosis during drilling, the temperature should not increase above $50^{\circ} \mathrm{c}$.

- Drilling speed is an important factor. From Hillery and Shuaib [1] experiment, he conducts that experiment with three different speeds. So increasing in speed reduces temperature produced during drilling.

- $115 \mathrm{~mm} / \mathrm{min}$ to $220 \mathrm{~mm} / \mathrm{min}$ of feed rate give more effective cutting and reduction in temperature. Because most of the experiments were conducted on that feed rate.

\section{REFERENCES}

[1]. M.T. Hillery, I. Shuaib, "Temperature effects in the drilling of human and bovine bone" Journal of Materials Processing Technology 1999 PP 302 \pm 308

[2]. G.J.M. Tuijthof, C. Frühwirtc, C. Kment, ' Influence of tool geometry on drilling performance of cortical and trabecular bone"' Medical Engineering \& Physics 2013 PP 1165- 1172

[3]. JuEun Lee, O. Burak Ozdoganlar, Yoed Rabin' An experimental investigation on thermal exposure during bone drilling" Medical Engineering \& Physics 2012 PP 15101520
[4]. Wendong Wang, Yikai Shi, Ning Yang, Xiaoqing Yuan " Experimental analysis of drilling process in cortical bone" Medical Engineering \& Physics 2014 PP 261- 266

[5]. Wuhu Rui Jin Medical Instrument \& Device Co., Ltd China

[6]. Rupesh Kumar Pandey, S.S. Panda. ''Bone drilling compressive review" journal of clinical orthopedics and trauma 2013 PP 15-30

[7]. Yoed Rabin, O. Burak Ozdoganlar "' A new thermal model for bone drilling with applications to orthopaedic surgery', Medical Engineering \& Physics 2011 PP12341244

\section{BIOGRAPHIES}

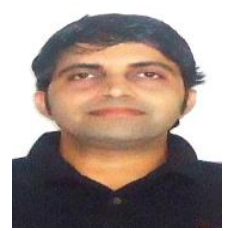

Dr. Govindan P. received his B.Tech degree in Mechanical Engineering from Kannur University, India, in 2001, the M.Tech. degree in CIM from IIT Madras, Chennai, India, in 2003, and the Ph.D. degree in Advanced Manufacturing technology from IIT Bombay, Mumbai in Manufacturing Science, Mumbai, India, in 2012. He was a research assistant, assistant professor, lecturer with Department of Mechanical Engineering, GCE Kannur, from year 2006. His research interests include advanced manufacturing, material removal, metrology and hybrid machining. At present, He is engaged in activities related to a centre of excellence systems, energy and environment at GCE Kannur, Kerala, India

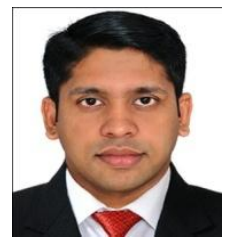

Mr. Ajish T.N received his B.Tech degree in Production engineering from Calicut University, India, in 2013, and presently doing his M.Tech degree in advanced manufacturing at Kannur University. Kerala, India. He conducts a quality improvement program in Kerala agricultural cooperation, Athani, Kerala. Presently his project is based on medical field, thermal effects during bone drilling. His research interests include micro manufacturing, nano-machining, semi solid metal processing. 